\title{
An investigation on the growth of breast-fed children and children fed with formula feed under the age of one year in Ilam, Iran
}

\author{
Jasem Mohamadi ${ }^{1}$ and Mohamad Reza Havasian²* \\ ${ }^{1}$ Department Pediatrics, Faculty of Medicine, Ilam University of Medical Sciences, Ilam, Iran \\ ${ }^{2}$ Department Periodontics, School of Dentistry, Ilam University of Medical sciences, Ilam, Iran
}

\begin{abstract}
Despite global emphasis on exclusively breast feeding children during the first six months of life, most mothers stop breast feeding their children. The continuation of complementary feeding can prevent various diseases and even decrease the risk of developing asthma in childhood in vulnerable families by 50\%. The present descriptive-cross sectional study aims at investigating the growth of breastfed children and children fed with formula under the age of one year in Ilam. The investigated population consists of all the infants who visited urban health centers in Ilam to receive monthly care during winter in 2009. The investigated children were divided into two groups: breastfed children and children fed with formula. Researcher-developed questionnaires were used to gather information on the infants. The gathered data on the infants included demographic data, growth indices, and their parents' history of underlying diseases. The data were analyzed using SPSS version 16. In this study, 195 patients were investigated, of whom 96 cases (49.2\%) were males and 99 cases (50.8\%) were females. The highest frequency was for mothers aged 24-28. Furthermore, 108 cases (55.4\%) were breastfed children and 87 cases (44.6\%) were children fed with formula. Four cases $(2.1 \%)$ of breastfed children and 9 cases $(4.6 \%)$ of the children fed with formula suffered from FTT with average heights. Moreover, 4 cases $(2.1 \%)$ of breastfed children and 5 cases $(2.6 \%)$ of the children fed with formula suffered from FTT with average weights. The results of the study indicate that feeding children with breast milk until the age of six months and its continuation late on can considerably decreases weight and height disorders and also the number of admissions to the hospital due to diarrhea.
\end{abstract}

KEY WORDS: GROWTH, BREASTFED, FORMULA, CHILDREN

\section{ARTICLE INFORMATION:}

*Corresponding Author: havasian1991@gmail.com. Received $12^{\text {th }}$ March, 2017

Accepted after revision $20^{\text {th }}$ June, 2017

BBRC Print ISSN: 0974-6455

Online ISSN: 2321-4007 CODEN: USA BBRCBA

$\therefore$ Thomson Reuters ISI ESC and Crossref Indexed Journal

NAAS Journal Score 2017: 4.31 Cosmos IF : 4.006

- A Society of Science and Nature Publication, 2017. All rights reserved.

Online Contents Available at: http//www.bbrc.in/ 


\section{INTRODUCTION}

In recent years, there has been a global attention to the point that the beginning years of a child's life are a golden opportunity for effectively promoting children's development.The World Health organization has highlighted the importance of exclusively breastfeeding children within the first six months of a child's life. Exclusive breastfeeding provides an ideal diet for the child, improves the psychological relationship between mother and child, maintains the health of mother and child, and brings economic benefits, (Olds et al. 2002, Napoli et al. 2004, Mohammadi et al., 2017 and Behnampoor 2017).

Moreover, there is plenty of evidence demonstrating the benefits of breastfeeding, and breastfeeding is generally unavoidable (Cunningham et al. 1991). In developing countries, breastfeeding decreases infant mortality and diseases to a considerable degree. In developed countries, a great amount of evidence indicates that breastfeeding prevents the sudden death syndrome and the development of diabetes in teenage ages (Park et al. 1993). Furthermore, breastfeeding decreases the risk of gastrointestinal, urinary, and pulmonary infections and improves child's neural growth (Crawford et al. 1993). In fact, the considerable growth of infants within their first year of life, namely three times increase in weight, two times increase in height, and constant physical growth, albeit in a slower pace from the age of one year to puberty, creates certain nutritional needs. Moreover, unlike adults, these nutritional needs are affected by strong maintenance needs caused by constant metabolic and nutritional transformations in infants and children. Also, since this fast growth is accompanied by certain growth changes in performance and body composition, any defect in supplying an adequate amount of nutrients during this period of time can leave destructive effects not only on growth but also on development (Jenson et al. 2008).

Generally, starting feeding with breast milk within the first hour of life after birth and exclusive breastfeeding within the first six months of life can save the lives of more than one million infants. Breast milk can alone provide all the nutrients needed by an infant for a normal growth from the first moment of life through the end of the sixth month of life. Even within the first few days after birth, when the normal flow of milk in the breast of the mother is not established, the infant does not need any other food or drink, and that amount of milk would be enough to ensure the infant's natural growth. The living cells and various antimicrobial agents in breast milk, which can be found in a higher density in colostrum, can destroy bacteria, viruses, and parasites and, consequently, decrease the risk of the child being afflicted with infections, particularly gastro- intestinal and respiratory infections and the infections of the middle ear (Mohamadi et al. 2014).

Milk powder is merely a food while breast milk is a nutritious, organic, and complex liquid containing antibodies, enzymes, and hormones that are all useful for health. Besides, some methods of feeding the child with milk powder expose the child to serious risks of infection. Early receiving of colostrum, which is high in antibodies, has great importance in developing countries, and small amounts of colostrum can help the body prevent overloading the kidneys when the child is regulating body fluid balance (Hoddinott et al. 2008). According to international indicators, all infants should be breastfed right after their birth and in less than one hour after delivery, and even before they are washed and before their cord is cut. In fact, this is now one of the most important health indicators. To this end, there exists a need for adequately training the medicine and nursing team and retraining them about nutrition and breastfeeding (Behnampoor et al. 2017). The present study aims at investigating the growth of breastfed children and children fed with formula under the age of one year in Ilam.

\section{MATERIAL AND METHODS}

This is a descriptive-cross sectional study in which the investigated population consists of all the infants who visited nine urban health centers affiliated with the health network of Ilam province to receive monthly care during winter in 2009. To this end, after obtaining written permission for conducting the research from the research office of Ilam University of Medical Sciences and gaining approval from university's research ethics committee, the research was carried out in the health centers mentioned above. The investigated infants were divided into two groups: breastfed infants and infants fed with formula. Information about people were gathered using two researcher-developed questionnaires that included demographic data and growth indices such as age, sex, their parents' level of education and history of underlying diseases. Parametric and non-parametric tests were used to compare the variables and investigate the relations and correlations among them. For this purpose, the data were analyzed using SPSS version 16, and Chi-Square tests and T-tests were performed (Havasian et al. 2012, Mahmoodi et al. 2017 and Mohamadi et al. 2017).

\section{RESULTS AND DISCUSSION}

In this study, 195 patients were investigated, of whom 96 cases (49.2\%) were males and 99 cases (50.8\%) were females. The highest frequency of patients was for 
Table 1 . Frequency of investigated infants by age

\begin{tabular}{|l|l|l|}
\hline Age (Months) & Frequency & Percent \\
\hline 3 and Less & 60 & 30.7 \\
\hline $3-6$ & 73 & 37.4 \\
\hline $6-9$ & 41 & 21 \\
\hline 9 and More & 21 & 10.7 \\
\hline Total & 195 & 100 \\
\hline
\end{tabular}

infants aged 3-6 months; they comprised $37.4 \%$ of the infants. The lowest frequency was for infants under the age of nine months and above; they comprised 10.7\% of the infants (Table 1). The highest frequency among mothers was for mothers aged 24-28 years who comprised $32.8 \%$ of mothers, and the lowest frequency was for mothers aged 34 and above who comprised 17.9\% of mothers (Table 2). The highest frequency for mother's level of education was for mothers with a diploma and lower who comprised $64.1 \%$ of the mothers with 125 cases. Of the investigated infants, 108 cases (55.4\%) were fed with breast milk and 87 cases (44.6\%) were fed with formula. Also, the most common reason for using formula was lack of breast milk in 47 cases (56.4\%) and the least common reason was death of mother in two cases (1.3\%) (Table 3). Four cases of the investigated infants in the breastfed infants group (2.1\%) and nine cases in the infants fed with formula group (4.6\%) suf-

\begin{tabular}{|l|l|l|}
\hline \multicolumn{4}{|l|}{ Table 2. Frequency of investigated infants by the } \\
age of infant's mother \\
\hline Age of mother (Years) & Frequency & Percent \\
\hline $18-23$ & 40 & 20.5 \\
\hline $24-28$ & 64 & 32.8 \\
\hline $29-33$ & 56 & 28.7 \\
\hline 34 and more & 35 & 17.9 \\
\hline Total & 195 & 100 \\
\hline
\end{tabular}

\begin{tabular}{|c|c|c|}
\hline $\begin{array}{l}\text { Reason for feeding } \\
\text { with formula }\end{array}$ & Frequency & Percent \\
\hline Weak breast milk & 9 & 10.5 \\
\hline Employment of mother & 24 & 28 \\
\hline Lack of breast milk & 47 & 54.6 \\
\hline Disease of mother & 4 & 5 \\
\hline Death of mother & 2 & 2.3 \\
\hline Total & 86 & 100 \\
\hline
\end{tabular}

fered from FTT with average levels of height (Table 4). Four cases of the investigated infants in the breastfed infants group (2.1\%) and five cases in the infants fed with formula group (2.6\%) suffered from FTT with average levels of weight (Table 5). The means for height, weight, head circumference for breastfed infants were $62.99 \mathrm{~cm}, 67 \mathrm{~kg}$, and $41 \mathrm{~cm}$, respectively. In infants fed with formula the mean height, weight, and head circumference were $60.89 \mathrm{~cm}, 63 \mathrm{~kg}$, and $40 \mathrm{~cm}$, respectively $(\mathrm{P}>0.05)$. The highest number of admissions to the hospital due to diarrhea and type of nutrition was two times in three cases of the infants fed with formula (Table 6). Infants fed with breast milk do not need water or iron until the age of six months; the breast milk provides all the required nutrients and liquids to maintain the infant's health (Martinez et al. 2002).

In fact, breastfeeding is the most important and the most effective factor in maintaining and sustaining infants' health that has been approved by all academic circles around the world (Shadzi et al. 2000). The continuation of breastfeeding after the start of complementary feeding can prevent various diseases such as pneumonia, urinary tract infection, middle ear infection, diarrhea, bacteremia, and bacterial meningitis, and decreases the risk of developing asthma in vulnerable families by $50 \%$ (Weinstein et al. 2006). Weight is an important indicator of physical growth and development and is the simplest and, at the same time, one of the best indicators of growth. The weight of 95\% of term infants is $2.5-4.6 \mathrm{~kg}$, with a mean of $3.4 \mathrm{~kg}$. Boys tend to be slightly heavier than girls (Ardabili et al. 2008). An infant loses around 5-10\% of its weight within the first few days after birth and returns to its weight at birth from seven to ten days after birth (Jenson et al. 2008). Furthermore, the benefits of feeding infants who weigh less than $1500 \mathrm{gr}$ with breast milk has recently been 


\begin{tabular}{|c|c|c|c|c|c|}
\hline \multirow{2}{*}{ Keight FTT } & \multicolumn{2}{|c|}{ Fed with Formula } & \multicolumn{2}{|l|}{ Breastfed } & \multirow{2}{*}{ Total } \\
\hline & Frequency & Percent & Frequency & Percent & \\
\hline Lack of FTT & 57 & 29.2 & 84 & 43.1 & 141 \\
\hline Light & 16 & 8.2 & 15 & 7.7 & 31 \\
\hline Moderate & 9 & 4.6 & 4 & 2.1 & 13 \\
\hline Severe & 5 & 2.6 & 5 & 2.6 & 10 \\
\hline Total & 87 & 44.6 & 108 & 55.4 & 195 \\
\hline
\end{tabular}

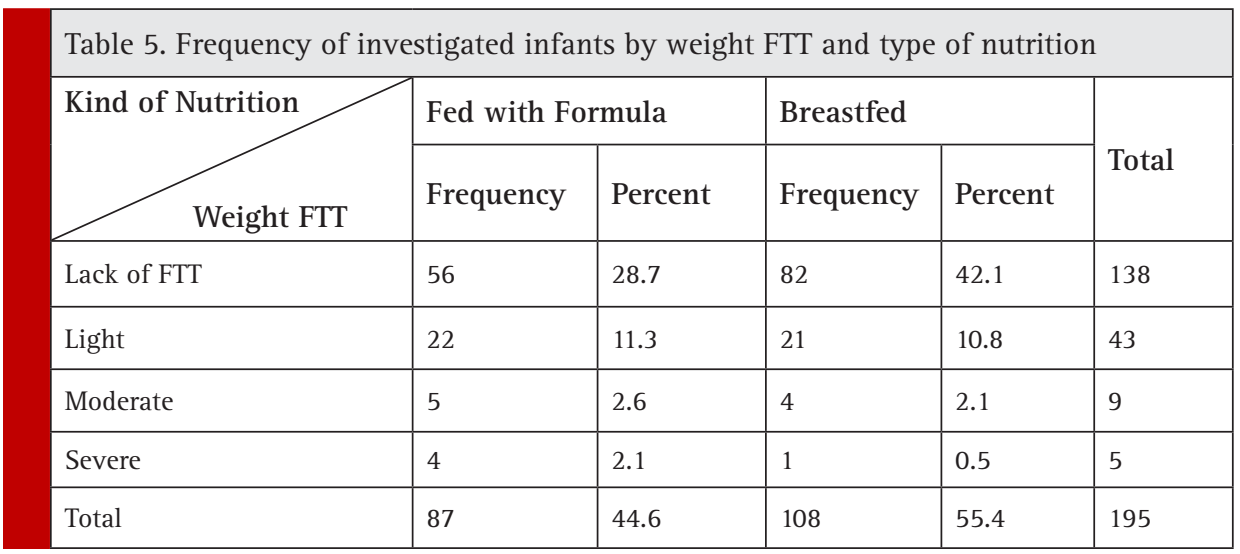

recognized, and breastfeeding is the most preferable way of feeding infants (Schanler et al. 2005). Given the above-mentioned discussion, the present study investigated the growth of breastfed children and children fed with formula in Ilam. In the study of Ziaa et al 2009, which was conducted to investigate the effect of type of delivery on the success of breastfeeding, breastfeeding had started within the first hour after delivery by 207 mothers (60\%) Findings of Islami et al. (2008), also correspond with the results found in the present study.

The results of Jokar et al (2009), which investigated the effects of auxiliary nutrition in children under the

\begin{tabular}{|c|c|c|c|c|c|}
\hline \multirow[t]{2}{*}{ Kind of Nutrition } & \multicolumn{2}{|c|}{ Fed with Formula } & \multicolumn{2}{|l|}{ Breastfed } & \multirow{2}{*}{ Tota } \\
\hline & Frequency & Percent & Frequency & Percent & \\
\hline Without disease history & 79 & 40.5 & 104 & 53.3 & 183 \\
\hline Once & 5 & 2.6 & 4 & 2.1 & 9 \\
\hline Twice & 3 & 1.5 & 0 & 0 & 3 \\
\hline Total & 87 & 44.6 & 108 & 55.4 & 195 \\
\hline
\end{tabular}


age of on year who had visited clinics in Ilam, indicated that $69.9 \%$ of the mothers were housewives, and most of them were aged 18-24 years, and most of them had a diploma or a lower degree of education (Jokar et al. 2008), which are in line with the results of the present study. In another study, it was reported that the prevalence of giardia infection was 45.5\% among infants fed with breast milk, 9.3\% in infants fed with milk powder, and $17.7 \%$ in infants fed with cow milk (Ghorbani et al. 2008). In the present study, admission to the hospital for more than one time was significantly higher among infants fed with formula. In Mihrshahi et al (2003), which investigated the relationship between the prevalence of respiratory infections and the length of exclusive feeding of infants with breast milk, it was reported that the prevalence of respiratory diseases is related with shorter periods of exclusive feeding with breast milk (Mihrshahi et al. 2007), a finding in line with the results of the present study.

In Helena et al 2008, which investigated the effect of breastfeeding on the growth of 479 infants in a health center in Brazil, the results of the study showed that, despite a faster growth in the beginning months of their lives, breastfed children reached lower weight and height balances compared to infants fed with milks other than breast milk in the same period of time (Spyrides et al. 2008). However, in the present study, the means for height and weight disorders in infants fed with formula was higher than the means for breastfed children, a finding not in line with Helena et al, 2008. Generally, in many studies, mothers have stated that they are not supported by health staff and do not have access to them when they need them. In fact, mothers point to lack of access to health staff as an impeding factor in sustaining breastfeeding, which is line with the results of the present study.

\section{CONCLUSION}

The results of the present study indicated that breastfeeding until the age of six months and its continuation late on can considerably decrease weight and height disorders and the number of admissions to the hospital due to diarrhea. We suggested that further research be done to investigate different aspects of breastfeeding and the importance of educating mothers who visit health centers about the problems and disadvantages of feeding with formula.

\section{REFERENCES}

Ardabili E, Rafaie-Shirpak H. (2008). Public Health. Ministry of Health and Medical Education. $3^{\text {th }}$ Edition.
Behnampoor M, Havasian MR, Sargolzaei N, Mahmoodi Z, Salarzaei M, Mohamadi J. (2017). Investigating the Mortality Causes of 1-59 Months Babies of Village from 2012 to 2015, Zahedan, Iran. Indo Am. J. P. Sci. 4(05): 1079-84.

Crawford MA. (1993). The role of essential fatty acids in neural development: implications for perinatal nutrition. The American journal of clinical nutrition. 57(5): 703S-9S.

Cunningham AS, Jelliffe DB, Jelliffe EP. (1991). Breast-feeding and health in the 1980s: a global epidemiologic review. The Journal of pediatrics. 118(5): 659-66.

Ghorbani R, Sadat-Hashemi SM, Pazooki R. (2008). Does breast-feeding protect the child from Giardia lamblia infection?. J of Tehran Uni Med. 66(6): 425-31.

Havasian MR, Panahi J, Khosravi A. (2012). Correlation between the lipid and cytokine profiles in patients with coronary heart disease (CHD)(Review article). Life Science Journal. 9(4): 5772-77.

Hoddinott P, Tappin D, Wright C. (2008). Breast feeding. BMJ. 336(7649): 881-87.

Islami Z, Fallah R, Golestan M, Shajaree A. (2008). Relationship between Delivery Type and Successful Breastfeeding. Iran J Pediatr. 18(Suppl 1): 47-52.

Jenson MD. (2008). Nelson textbook of pediatrics, $18^{\text {th }}$ Edition. Jokar F, Taheri-Ezirmi Z, Yeganeh MR. (2008). Supplementary nutrition status of children under one year old in Ilam clinics. J of Hayat. 14(1): 61-8.

Mahmoodi Z, Havasian MR, Esmail-Zahikurin, Salarzaei M. (2017). Investigating Critical Blood Pressure Risk Factors in Zabol, Amir-Al-Momenin Hospital Patients in 2015-2016. Indo Am. J. P. Sci. 4(05): 1183-87.

Martinez CS. (2002). FNRI Recommends Exclusive BreastFeeding for the First Six Months.

Mihrshahi S, Ichikawa N, Shuaib M, Oddy W, Ampon R, Dibley MJ, Kabir AI, Peat JK. (2007). Prevalence of exclusive breastfeeding in Bangladesh and its association with diarrhoea and acute respiratory infection: results of the multiple indicator cluster survey 2003. Journal of Health, Population and Nutrition. 25(2): 195-204.

Mohamadi J, Darabi M, Havasian MR. (2017). Investigating the Causes of Infant Mortality in Imam-Khomeini and MustafaKhomeini Hospitals, Ilam, 2012 To 2016. Indo Am. J. P. Sci. 4(06): 1431-37.

Mohamadi J, Motaghi M, panahi J, Havasian MR, Delpisheh A, Azizian M, Pakzad I. (2014). Anti-fungal resistance in candida isolated from oral and diaper rash candidiasis in neonates. Bioinformation. 10(11): 667-70.

Napoli A, Lallo D, Fortes C, Franceschelli C, Armeni E, Guasticchi G. (2004). Home breastfeeding support by health professionals: findings of a randomized controlled trial in a population of Italian women. Acta Paediatrica. 93(8):1108-14.

Olds LD. (2002). Prenatal and infancy home visiting by nurses: from randomized trials to community replication. Prevention Science. 3(3):153-72. 
Park P. (1993). Cow's milk linked to juvenile diabetes. New Scientist. 22(5): 1835-39.

Schanler RJ. (2005). Enteral nutrition for the high-risk neonate. Taeusch WH, Ballard RA, Gleason CA: Avery's Diseases of the Newborn, Ed Elsevier Saunders.

Shadzi SH. (2000). Principles to children's health. Isfahan, Kankash publication.
Spyrides MH, Struchiner CJ, Barbosa MT, Kac G. (2008). Effect of predominant breastfeeding duration on infant growth: prospective study using nonlinear mixed effect models. Jornal de pediatria. 84(3): 237-43.

Weinstein ME, Oleske JM, Bogden JD. (2006). A selected review of breast-feeding recommendations. Nutrition research. 26(8): 379-84. 